Transactions of the SDPS:

Journal of Integrated Design and Process Science

$21(2), 2017,1-2$

DOI 10.3233/jid-2017-0015

http://www.sdpsnet.org

\title{
Editorial
}

\section{Design Education and Engineering Design}

\author{
Kyoung-Yun Kim ${ }^{a}$, Gül E. Okudan $\mathrm{Kremer}^{b}$, Linda Schmidt ${ }^{c}$ \\ ${ }^{a}$ Department of Industrial and Systems Engineering, Wayne State University, Detroit, MI, USA \\ ${ }^{b}$ Department of Industrial and Manufacturing Systems Engineering, Iowa State University, Ames, IA, \\ USA
}

${ }^{c}$ Department of Mechanical Engineering, University of Maryland, College Park, MD, USA

Engineering design has been a focus of study not only due to its practical importance for the engineering and technology development domains, but also due to its rich setting that naturally supports cognitive and behavioral investigations of designing, learning, and teaming. It mostly involves ill-structured problem solving, which makes the act of designing and design education complex. This problem context often includes fundamental design, customization, personalization, and domain specific engineering issues. The multi-stage problem solving skills, for example, can be enhanced by integrating real-world problems to the design problem context - an aspect that also brings ill-structuredness.

Given the importance of engineering design, scholars from both engineering design and science of problem solving domains, and indeed many others such as education, psychology, mechanical engineering, business, artificial intelligence, contributed to the state-of-the-art on this focus. To name a few, many approaches based on various education theories, including project-based learning (PBL) (Blumenfeld et al., 1991), inquiry-based learning (Schwab, 1960; Herron, 1971), discovery learning (Bruner, 1961, 2009), constructivism and constructionism (Papert 1996, 1998), have been studied to increase our deep understanding of learners in design education domains. These approaches often consider individual and group design activities. Yet, there are aspects of designing that are still difficult to replicate in laboratory conditions and practice in classroom settings.

This special issue includes five articles that broaden our understanding of how design education can be redesigned with instructional design principles and exemplify the role of education design to advance design education. The selected articles present recent research advances on learning technology and pedagogical experiments informed by theories of learning and design.

The first article, "Translating Constructionist Learning to Engineering Design Education" by Psenka et al. provides an account of the constructionist paradigm from the perspective of engineering design education. Authors discuss the history of constructivist principles of learning and how constructionist concept was developed by Papert with historical roots in Piaget's constructivism. The educational reform movement of constructionism is further discussed with multiple examples including LEGO/Logo, Game

\footnotetext{
* Corresponding author. Email: kykim@,wayne.edu
} 
Design, Fab Lab, makerspaces, the Maker movement, and the Computer Clubhouse. This article highlights the role of constructionism for designing engineering design education, as well as challenges the traditional engineering design curricula. The authors suggest creating a 'Designland' or learning incubator similar to Papert's Mathland to enhance engineering design education.

The second article, "On the Factors Affecting Design Education within a Multi-disciplinary Class" by Cascini et al. presents educational experience in the Design Methods and Processes jointly developed by two universities. This article focuses on the multi-disciplinary nature of the design course. Specifically, the authors share their experience and reflect on the challenges they faced to construct the course content by structuring the educational path as a problem-analysis-and-solving process to explain the design workflow to students. The series of inquiries and quantitative analysis are aligned to measure Problem-Based Learning in the context of a multi-disciplinary design course.

The third article, "Integrated Engineering Design Education: Vertical and Lateral Learning" by AlDojayli and Czekanski is about recent efforts to construct engineering design curriculum. In this article, the authors introduce vertically and laterally integrated engineering design education and learning. With this framework, the basic and interdisciplinary engineering courses (including design economics, social and environment impacts, ethics and regulatory issues, and global and cultural impacts) are designed, and aligned toward integrated engineering design curriculum.

The fourth article, "Exposure to Digital and Hands-on Delivery Modes in Engineering Design Education and their Impact on Task Completion Efficiency" by Ma et al. compare hands-on (tactile) and digital (visual) models and their efficiency in the context of engineering design education. The authors describe performance of these two modes using engagement time, and taking into account prior digital and tactile hands-on skills as factors to impact on task performance. The results of the study explain the advantages of hands-on learning (comparing to digital technologies) for engineering design learning.

Lastly, "From Environment Based Design to Linguistics Education" by Yi et al. is an implementation case that applies a design theory, Environment Based Design, to enhance the linguistics education curriculum. Specifically, this article shares the authors' experience in a translation course design within an undergraduate linguistics program. The article compares the effectiveness of the micro-lecture teaching method designed with Environment Based design and the traditional translation course practice.

As these articles illustrate, engineering design not only provides a logic (philosophy) to course design but also a process for how to accomplish it. Changing technology surrounding engineering design teaching, learning and practice sustains its mystery and promise as a complex and important cognitive and behavioral activity. We expect the exemplified bidirectional benefits between engineering design and design of instruction to continue.

\section{References}

Blumenfeld, P.C., Soloway, E., Marx, R.W., Krajcik, J.S., Guzdial, M., and Palincsar, A. (1991). Motivating Project-Based Learning: Sustaining the Doing, Supporting the Learning, Journal, Educational Psychologist, Volume 26, Issue 3-4, pp. 369 - 398.

Bruner, J. S. (1961). The act of discovery. Harvard Educational Review, 31, pp. 21-32.

Bruner, J. S. (2009). The process of education. Harvard University Press.

Papert, S. (1998). Child Power: Keys to the New Learning of the Digital Century. Eleventh Colin Cherry Memorial Lecture on Communication delivered on June 2, 1998, at the Imperial College in London.

Papert, S. (1996). A Word for Learning. InY. Kafai \& M. Resnick (Eds.), Constructionism in Practice: Designing, Thinking, and Learning in a Digital World. NJ: Lawrence Earlbaum.

Schwab, J. J. (1960). Inquiry, the science teacher, and the educator. The School Review, 68(2), pp. 176-195. Herron, M. D. (1971). The nature of scientific enquiry. The School Review, 79(2), pp. 171-212. 